\title{
Second-order conditioning: Different outcomes in fear and eyelid conditioning
}

\author{
ROBERTA S. POPIK, STEVEN D. STERN, and PETER W. FREY \\ Northwestern University, Evanston, Illinois 60201
}

\begin{abstract}
Second-order conditioning has been frequently observed with the fear response but not with the eyelid response. The present experiments manipulated the temporal relationship between the second-order and first-order stimulus on second-order conditioning trials. Our results indicated that a trace second-order procedure is not effective with either response system. Second-order fear conditioning was most prominent when the second-order CS terminated at the onset of the first-order CS. This arrangement, however, did not produce second-order eyelid CRs. In eyelid conditioning, the second-order CS appears to inhibit responding to the first-order CS which immediately follows it.
\end{abstract}

Pavlov (1927, p. 33) reported that a response originally conditioned to one stimulus could be conditioned to another when the two were paired in the absence of the US. Investigations employing the conditioned fear response have demonstrated reliable second-order conditioning. McAllister and McAllister (1964) trained rats to hurdle-jump to avoid shock. A group which received forward pairings of the second-order and first-order stimulus ( $\mathrm{CS}_{2}$ and $\mathrm{CS}_{1}$, respectively) showed consistent secondorder responding, whereas a backward conditioning control group did not. Other control procedures, such as noncontingent presentations of either $\mathrm{CS}_{1}$ and the US (Rizley \& Rescorla, 1972, Experiment 1) or $\mathrm{CS}_{2}$ and $\mathrm{CS}_{1}$ (Kamil, 1968), have also been examined. These studies demonstrate that both $\mathrm{CS}_{1}$ and the US, as well as $\mathrm{CS}_{2}$ and $\mathrm{CS}_{1}$, must be paired in order for responding to $\mathrm{CS}_{2}$ to develop. These outcomes clearly establish second-order fear conditioning as a bona fide associative phenomenon.

In contrast, investigations of second-order conditioning with the eyelid response have not been notably successful. Maisiak and Frey (1977, Experiment 2) established stable responding to $\mathrm{CS}_{1}$ and then presented conditioning sessions containing both $C S_{1}-U S$ and $C S_{2}-C S_{1}$ trials. Very few second-order CRs were observed. Overall responding to $\mathrm{CS}_{2}$ was less than 2\%. A companion study (Maisiak \& Frey, 1977, Experiment 1), however, demonstrated reliable

The authors thank Nadia Wasylyshyn and Craig Landis for data-collection assistance in Experiment 2 as well as James Baker, Kim Ravunec. and Mark Matray for pilot work prior to Experiment 2. This research was supported by National Science Foundation Research Grant BMS75-02313. Requests for reprints should be directed to Peter W. Frey, 206 Cresap Laboratory, Northwestern University, Evanston, Illinois 60201. Roberta S. Popik is now at Northeastern Illinois University, Department of Educational Foundations, 5500 N. St. Louis Avenue, Chicago, Illinois 60625 . second-order fear conditioning with an analogous set of procedures.

The difficulty in obtaining second-order eyelid conditioning may be due to the use of an inappropriate time relationship between $\mathrm{CS}_{2}$ and $\mathrm{CS}_{1}$. This hypothesis is based on Pavlov's (1927, p. 33) specification that for second-order conditioning to be effective, a temporal gap must separate $\mathrm{CS}_{2}$ and $\mathrm{CS}_{1}$; i.e., "the essential condition is that the new stimulus should be withdrawn some seconds before the primary stimulus is applied." Fear conditioning data have not supported this notion. For example, Maisiak and Frey (1977, Experiment 1) found that second-order fear conditioning was less probable when a gap separated $\mathrm{CS}_{2}$ and $\mathrm{CS}_{1}$ than when the onset of $\mathrm{CS}_{1}$ coincided with the termination of $\mathrm{CS}_{2}$. Similarly, Rescorla (1973) found that a delay secondorder fear conditioning procedure was superior to a trace procedure. The present experiments provide a more detailed analysis of Pavlov's hypothesis by systematically manipulating the temporal relationship of $\mathrm{CS}_{2}$ and $\mathrm{CS}_{1}$ in second-order conditioning.

\section{EXPERIMENT 1}

\section{Method}

Subjects. The subjects were 48 male albino rabbits ranging from 15 to 20 weeks in age and weighing approximately $1.8 \mathrm{~kg}$. The animals were housed individually with free access to water and Purina Rabbit Chow. Four animals died of respiratory infections, and their data were eliminated. The colony room was maintained at $21^{\circ} \mathrm{C}\left( \pm 1^{\circ}\right)$ and $50 \%$ relative humidity $( \pm 15 \%)$. The overhead fluorescent lights were on from 7 a.m. to 8 p.m. daily.

Apparatus. The conditioning equipment used in the present study was similar to that described in Frey and Butler (1977, Experiment 2). The rabbits were conditioned in a large walkin chamber (2.6 m long, $2.0 \mathrm{~m}$ wide, and $2.1 \mathrm{~m}$ high). Its temperature $\left(20^{\circ} \mathrm{C}, \pm 1^{\circ}\right)$ and humidity $(50 \%$ relative, $\pm 10 \%)$ were kept relatively constant. A Grason-Stadler (Model 901B) white- 
noise generator maintained the background sound level in the chamber at $74 \mathrm{~dB}$ SPL. The animals were individually restrained within Plexiglas and aluminum stocks, A photoelectric system (see VanDercar, Swadlow, Elster, \& Schneiderman, 1969) and a six-channel oscillograph (Beckman Model 504D) graphically recorded eyelid movements.

The first-order CS was a flashing light consisting of two small light bulbs (Chicago Miniature No. 1820), each mounted behind a plastic translucent lens cap. The bulbs were $5 \mathrm{~cm}$ apart and positioned approximately $12.5 \mathrm{~cm}$ in front of the rabbit's head and $12.5 \mathrm{~cm}$ above its eye level. The lights flashed alternately, somewhat like a railroad crossing, except at a faster rate $(5 \mathrm{~Hz})$. The second-order CS was a $3,000-\mathrm{Hz}$ tone presented at $10 \mathrm{~dB}$ over the background noise level in the conditioning chamber. The US was a 100 -msec constant current (4-mA) electric shock delivered through two stainless steel electrodes.

Procedure. The rabbits were habituated to their cages for at least 2 days prior to surgery. After being anesthetized, they were surgically prepared for conditioning by the placement of two cheek electrodes (25-ga stainless steel wire) just below and to either side of the right eye. Two stainless steel bolts $(2.56 \times$ $13 \mathrm{~mm}$ ) were embedded into the skull to the animal's left and right of bregma and resting on the dura. A third bolt $(2.56$ $\times 5 \mathrm{~mm}$ ), placed to the left of bregma, was used for additional support in conjunction with a covering layer of dental cement. The animal's skin was sutured over the cement platform.

After a 2-day recovery period, each animal had a 45-min habituation session in the restraining stock with the recording equipment attached. Acquisition training involved six sessions (Days 1-6), each consisting of $30 \mathrm{CS}_{1}$-US trials at a 90 -sec intertrial interval (ITI). The duration of $\mathrm{CS}_{1}$ was $600 \mathrm{msec}$, and the $\mathrm{CS}_{1}$-US interval was $500 \mathrm{msec}$. This was followed by two $50 \%$ reinforcement sessions (Days 7-8) designed to ensure stable responding to $\mathrm{CS}_{1}$ during the second-order conditioning phase which was to follow. The performance of the animals on the 6th day of acquisition was rank ordered. Nine animals failed to meet a criterion of $50 \%$ responding during that day and were eliminated from the experiment.

On Days 9.14, the animals received six sessions of second-order conditioning. Four different $\mathrm{CS}_{2}-\mathrm{CS}_{1}$ intervals were examined. The onset of the $500-\mathrm{msec} \mathrm{CS}_{2}$ occurred $500(n=8), 700$ $(\mathrm{n}=9), 1,000(\mathrm{n}=9)$, or $5,000(\mathrm{n}=9) \mathrm{msec}$ prior to the onset of $\mathrm{CS}_{1}$. The duration of $C S_{1}$ was $600 \mathrm{msec}$, and the $C S_{1}$-US interval was $500 \mathrm{msec}$. Each session consisted of 30 trials of an alternating presentation of $\mathrm{CS}_{1}$-US and $\mathrm{CS}_{2}-\mathrm{CS}_{1}$ trials. The temporal parameters for $\mathrm{CS}_{\mathrm{A}}$-US trials were the same as for acquisition. The ITI was maintained at $90 \mathrm{sec}$.

After completing second-order conditioning, each animal was given a threshold test (Day 15). Shock intensity was reduced to a level which just barely elicited an unconditional response (recorded measurement: approximately $5 \mathrm{~mm}$ in size). Four $\mathrm{CS}_{2}$ $\mathrm{US}_{\text {weak }}$ pairings were alternated with four $\mathrm{US}_{\text {weak }}$-alone trials. During the final phase of the experiment, the animals were given a transfer test which consisted of $30 \mathrm{CS}_{2}$-US pairings per session until each animal met a criterion of $10 \mathrm{CRs}$. The $\mathrm{CS}_{2}$-US interval was $500 \mathrm{msec}$ and the ITI was $90 \mathrm{sec}$.

\section{Results and Discussion}

The gain of the recording instruments was adjusted so that a complete eyelid closure produced a nearmaximal pen deflection for our recording system (i.e., 20-25 mm). A CR was defined as a pen movement of at least $1 \mathrm{~mm}$ in the appropriate direction between the onset of the CS and the onset of the stimulus which followed.

As has been the case with previous eyelid condi- tioning studies (Maisiak \& Frey, 1977, Experiment 2; Stern \& Frey, 1978, Experiment 2), there were very few overt second-order CRs. All groups showed less than $3 \%$ responding to $\mathrm{CS}_{2}$.

For the threshold test, the dependent measure was a UR ratio that compared the mean amplitudes (millimeters) of the URs on $\mathrm{CS}_{2}-\mathrm{US}_{\text {weak }}$ trials to The URs on US ${ }_{\text {weak }}$-alone trials. There were no reliable differences among the groups' UR ratios; $\bar{X}$ $=1.20,1.15,1.20$, and 1.34 for Groups 500,700, 1,000 , and 5,000 , respectively. On the transfer test, subjects reached a criterion of $10 \mathrm{CRs}$ to $\mathrm{CS}_{2}$ at similar rates; $\bar{X}=54,64,73$, and 66 trials, for Groups $500,700,1,000$, and 5,000, respectively. These results imply that $\mathrm{CS}_{2}$ had gained neither excitatory nor inhibitory properties as a result of the second-order conditioning trials. The observed UR ratios on the threshold test and the rate of conditioning on the transfer test are similar for all groups. If $\mathrm{CS}_{\mathbf{2}}$ had gained excitatory or inhibitory properties, one or more of these groups should have differed from the implicit control subjects (Group 5,000).

An analysis of variance was used to examine performance to $\mathrm{CS}_{1}$. There were no reliable differences among groups in the number of trials needed to achieve a criterion performance level of $10 \mathrm{CRs}$ to $\mathrm{CS}_{1}$ during acquisition $(\overline{\mathrm{X}}=91$ trials). As shown in Table 1, performance to $\mathrm{CS}_{1}$ at the end of acquisition (Days 7 and 8) was similar for the four groups $(F<1.0)$. During the $50 \%$ reinforcement sessions (Days 7 and 8), responding was higher to $\mathrm{CS}_{1}$ on the $\mathrm{CS}_{1}$-alone trials than on the $\mathrm{CS}_{1}$-US trials $[F(1,31)=91.31, \mathrm{p}<.001]$. Since the two trial types were alternated, this result indicates that US presentation increased the likelihood of making a CR on the subsequent trial. This effect has been reported previously in rabbit eyelid conditioning (Frey \& Ross, 1967).

Responding to $\mathrm{CS}_{1}$ during the second-order conditioning phase was examined after performance had

Table 1

Frequency of Conditional Responses (CRs) to the First-Order Stimulus $\left(\mathrm{CS}_{1}\right)$ in Experiment 1 as a Function of the Duration of the Interstimulus Interval (ISI) on Second-Order Trials

\begin{tabular}{ccccc}
\hline & \multicolumn{4}{c}{ Percent CRs to $\mathrm{CS}_{1}$} \\
\cline { 2 - 5 } ISI & $\mathrm{CS}_{1}$-US & $\mathrm{CS}_{1}$ Alone & $\mathrm{CS}_{1}$-US & $\mathrm{CS}_{2}-\mathrm{CS}_{1}$ \\
\hline 500 & 55.2 & 77.3 & 69.7 & 44.2 \\
700 & 54.8 & 77.8 & 59.0 & \multicolumn{2}{c}{$\begin{array}{c}\text { Accond-Order } \\
\text { Conditioning }\end{array}$} \\
1,000 & 55.3 & 76.5 & 61.2 & 74.3 \\
5,000 & 51.5 & 65.5 & 50.6 & 78.3 \\
\hline
\end{tabular}

Note-ISIs are given in milliseconds. Acquisition trials took place on Days 7.8, second-order conditioning trials on Days 12-14. 
stablized (Days 12-14). The main effects of ISI and $\mathrm{CS}_{1}$-US vs. $\mathrm{CS}_{2}-\mathrm{CS}_{1}$ trial type were not significant $[\mathrm{F}(3,31)=1.06$ and $\mathrm{F}<1.0$, respectively $]$; there was a significant interaction between the two variables $[\mathrm{F}(3,31)=11.58, \mathrm{p}<.001]$. As shown in Table 1 , responding to $\mathrm{CS}_{1}$ on $\mathrm{CS}_{2}-\mathrm{CS}_{1}$ trials showed a large increase as the gap separating $\mathrm{CS}_{2}$ and $\mathrm{CS}_{1}$ was lengthened; however, responding to $\mathrm{CS}_{1}$ on $\mathrm{CS}_{1}$-US trials decreased slightly as the gap was increased. This systematic effect of the $\mathrm{CS}_{2}-\mathrm{CS}_{1}$ temporal manipulation on responding to $\mathrm{CS}_{1}$ on second-order trials indicates that $\mathrm{CS}_{2}$ can act as an inhibitor in respect to a stimulus which follows immediately after it even though the animal's response tendency to $\mathrm{CS}_{2}$ itself does not appear to be altered. One interpretation of this inhibitory effect is that $\mathrm{CS}_{2}$ becomes a discriminative stimulus (i.e., a safety signal), indicating a period when no US will be presented. An equally likely nonassociative interpretation is that $\mathrm{CS}_{2}$ simply masks the onset of $\mathrm{CS}_{1}$. Both of these explanations are consistent with the observation that this inhibitory effect was less prominent when $\mathrm{CS}_{2}$ terminated $500 \mathrm{msec}$ or more prior to the onset of $\mathrm{CS}_{1}$.

\section{EXPERIMENT 2}

There was no evidence of second-order conditioning with any of the ISI durations used in Experiment 1 . It is not clear whether Pavlov's expectations are incorrect or whether the anticipated results are simply not present in eyelid conditioning. Since the conditioned suppression paradigm has provided consistent nonartifactual second-order conditioning (e.g., Davenport, 1966; Kamil, 1968; Rizley \& Rescorla, 1972), Experiment 2 examined the ISI manipulation in fear conditioning.

\section{Method}

Subjects. The subjects were 96 male and female gerbils, ranging from 4 to 12 months in age. The animals were born and raised in our own colony and were individually caged. They were maintained on a 20-h food-deprivation schedule, with Purina Rat Chow being available for a 4-h feeding period immediately after each session. Water was constantly available. The gerbil colony was maintained at $23^{\circ} \mathrm{C}\left( \pm 1^{\circ}\right)$ and $50 \%$ relative humidity $( \pm 15 \%)$. Overhead fluorescent lights were on from 7 a.m. to 7 p.m. daily.

Apparatus. The gerbils were runway trained and tested for second-order conditioning in an automated runway which was enclosed in a sound-attenuating metal box. A detailed description of the runway appears elsewhere (Sears, 1978).

For second-order conditioning, the gerbils were individually placed in aluminum and Plexiglas boxes which were $61.0 \mathrm{~cm}$ long, $20.3 \mathrm{~cm}$ high, and $5.1 \mathrm{~cm}$ wide. A speaker was mounted in the center of the back wall of each box. The boxes were located within a walk-in, sound-attenuating chamber identical to the rabbit conditioning chamber described in Experiment 1. A Grason-Stadler (Model 901B) white-noise generator maintained the background noise level in the chamber at $76 \mathrm{~dB}$ SPL. A 10-flash/sec strobe light, which served as $\mathrm{CS}_{1}$, was attached to the ceiling, centered above the four conditioning boxes. The second-order CS was a $2,000-\mathrm{Hz}$ tone presented at $10 \mathrm{~dB}$ above the background white-noise level. This stimulus, in both the runway and the conditioning boxes, was generated by a Hewlett Packard audio oscillator. The US was a .5-sec 4-mA footshock which was delivered across the grid floor of the conditioning box.

Procedure. The food-deprivation schedule began 5 days prior to the onset of runway training. During each day of this period, several Noyes food pellets were placed in the gerbil's horra cage immediately before its $4-\mathrm{h}$ feeding. Acquisition of the runway response occurred during nine daily sessions (Days 1-9). The subjects received 10 trials per session with a 5 -sec delay between trials.

On Day 4 of runway training, off-the-baseline secondorder conditioning began. The mean cumulative approach time (i.e., time to traverse the distance between the startbox and goalbox) was calculated for each animal for Days 3 and 4 of runway training. The running speeds were rank ordered, and this information was used to assign the animals to six similar groups of 16 animals each. Five of the groups received two trials per session-a first-order trial followed by a second-order trial, at a 12-min ITI. On the $\mathrm{CS}_{1}$-US trial, a 5-sec strobe light presentation was followed immediately by the US. The groups differed in the duration of the ISI on $\mathrm{CS}_{2}-\mathrm{CS}_{1}$ trials. Its duration was $5,10,15,25$, or $125 \mathrm{sec}$, as measured from the onset of $\mathrm{CS}_{2}$ to the onset of $\mathrm{CS}_{1}$. The duration of $\mathrm{CS}_{2}$ was constant at $5 \mathrm{sec}$ and no US was presented on those trials. The time relationship for the 125 -sec group is similar to that commonly used for an unpaired control group. The animals in the sixth group provided a baseline measure of performance. That group received a single trial per day in which $\mathrm{CS}_{2}$ was paired with the US-that is, it received first-order excitatory conditioning with the tone CS (Group FO). This trial was presented at the same time in the session as the CS,-US trial was for the other groups $(12 \mathrm{~min})$. There were six daily sessions of second-order conditioning (Days 4-9).

Upon completion of the runway training and the off-thebaseline second-order conditioning phases on Day 9, there were two test sessions in the automated runways (Days 10 and 11). All animals were treated the same as during the runway training sessions, with the exception that, on Trials 4 and $7, \mathrm{CS}_{2}$ was presented for $5 \mathrm{sec}$ simultaneously with the opening of the startbox door.

\section{Results and Discussion}

The dependent measure used for examining the excitation that developed to $\mathrm{CS}_{2}$ was the amount of suppression of the ongoing runway response. A suppression ratio was defined as $\alpha /(\alpha+\beta)$, where $\alpha$ was the mean approach speed (centimeters per second) on the two test trials in which the tone was presented and $\beta$ was the mean approach speed on the trials immediately preceding and following the test trials (i.e., Trials $3,5,6$, and 8 ). A suppression ratio of 0 indicates that the stimulus had acquired complete suppressive properties, whereas a ratio of .5 indicates that it had no suppressive properties.

A trend analysis for unequal intervals (Myers, 1972 , p. 386) was conducted on the mean suppression ratios across the 2 days of testing as a function of log seconds ISI. This analysis was done for the five groups in which a temporal gap was introduced between $\mathrm{CS}_{2}$ and $\mathrm{CS}_{1}$. As may be seen in Figure 1, the amount of suppression increased as the duration of the ISI was shortened [linear component $F(1,60)$ 


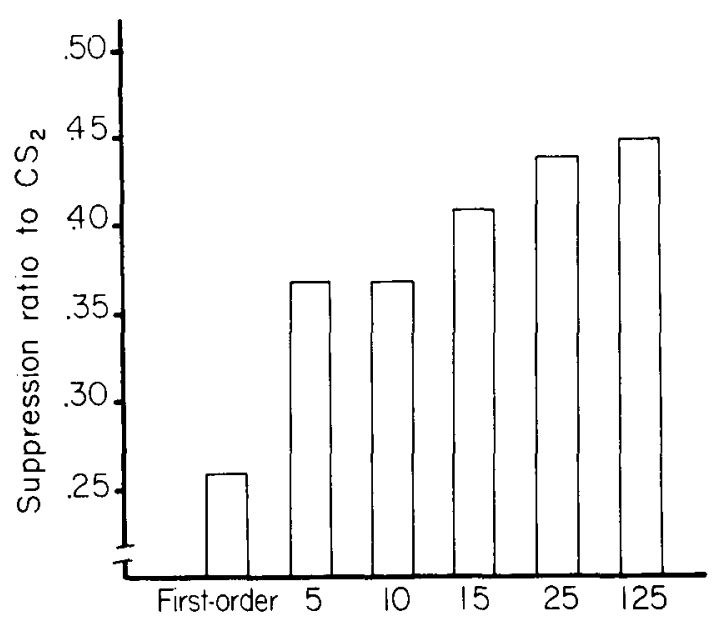

Figure 1. Amount of suppression to the second-order stimulus $\left(\mathrm{CS}_{2}\right)$ during the test sessions following second-order conditioning. Groups $5,10,15,25$, and 125 differed in the time interval between the onset of $\mathrm{CS}_{2}$ and the onset of $\mathrm{CS}_{1}$ on second-order trials. Training for the first-order group consisted of pairing $\mathrm{CS}_{\mathbf{2}}$ with the US, i.e., regular first-order conditioning.

$=10.98, \mathrm{p}<.01]$. As also shown in Figure 1, Group FO evidenced reliably more suppression of the runway response than Group $5[t(30)=4.67$, $p<.001]$. This suggested that the degree of excitation established as a result of second-order conditioning was not as great as that found with a normal first-order conditioning procedure.

Experiment 2, using the conditioned suppression paradigm, demonstrated reliable second-order conditioning. Group 5 reliably showed more suppression than Group $125[\mathrm{t}(30)=2.68, \mathrm{p}<.02]$. In addition, the results indicated that the temporal gap that was interposed between $\mathrm{CS}_{2}$ and $\mathrm{CS}_{1}$ for Groups 10,15 , and 25 did not facilitate second-order conditioning. This finding clarifies the interpretation of Experiment 1. The temporal relationship between $\mathrm{CS}_{2}$ and $\mathrm{CS}_{1}$ is important in second-order fear conditioning, with the optimal arrangement being either a short gap or simultaneous offset and onset. The temporal arrangements employed in Experiment 1, therefore, should have been successful if our secondorder eyelid conditioning procedure was viable in other respects.

\section{GENERAL DISCUSSION}

The present experiments examined whether second-order conditioning has not been observed with the eyelid response because the first- and secondorder stimuli have been presented in an inappropriate temporal relationship. In Experiment 1, there was an absence of second-order eyelid conditioning with all of the interstimulus intervals examined. With the fear response in Experiment 2, reliable second-order con- ditioning was observed when the onset of the firstorder stimulus coincided with the termination of the second-order stimulus. Extending the interval between the first- and second-order stimulus produced a decrease in the amount of second-order conditioning. This implies that the negative results observed with second-order eyelid conditioning in Experiment 1 would not have been changed if additional $\mathrm{CS}_{2}-\mathrm{CS}_{1}$ separations had been examined.

The virtual absence of second-order eyelid conditioning in Experiment 1 is consistent with other eyelid research (Maisiak \& Frey, 1977, Experiment 2; Stern \& Frey, 1978, Experiment 2). In each of these studies, as well as in the present investigation, attempts were made to maximize the possibility of observing second-order CRs. These included continued reinforcement of the first-order CS during second-order conditioning to insure that $\mathrm{CS}_{1}$ would not extinguish, the introduction of a partial reinforcement schedule toward the end of the first-order conditioning phase to minimize generalization decrement at the beginning of second-order conditioning, and an examination of several time relationships between the first- and second-order stimulus. In addition, threshold and transfer tests were given, both of which are relatively sensitive follow-up procedures. Despite these efforts, little evidence for second-order eyelid conditioning was observed.

Pavlov (1927) was concerned about striking a balance between a complete overlap of $\mathrm{CS}_{2}$ and $\mathrm{CS}_{1}$ producing conditioned inhibition and a large separation of $\mathrm{CS}_{2}$ and $\mathrm{CS}_{1}$ producing no conditioning at all. He believed that second-order conditioning was probable when an intermediate temporal relationship was employed and that inhibition was probable when $\mathrm{CS}_{2}$ and $\mathrm{CS}_{1}$ overlapped. This idea is consistent with the data from several studies in which extended conditioning was given with $\mathrm{CS}_{2}$ preceding and overlapping $\mathrm{CS}_{1}$ (e.g., Herendeen \& Anderson, 1968; Rescorla, 1972, 1973). In these studies, an initial excitatory phase of responding was followed by a subsequent inhibitory phase.

An interesting observation in Experiment 1 was that $\mathrm{CS}_{2}$ had an inhibiting influence on $\mathrm{CS}_{1}$ when the two stimuli occurred close together in time on second-order trials (Groups 500 and 700). This inhibitory effect, however, is not equivalent to that produced by a true conditioned inhibitor. Hearst (1972) and Rescorla (1969) have operationally defined conditioned inhibition in terms of the joint demonstration of reduced responding on a summation test and slower acquisition on a transfer test. The threshold test we employed provides essentially the same information as a summation test. Therefore, the negative results we observed with the threshold and transfer tests provide evidence that $\mathrm{CS}_{2}$ was not a conditioned inhibitor. Apparently $\mathrm{CS}_{2}$ has a 
prominent inhibitory influence on stimuli which follow it, but little or no inhibitory effect during its own presentation. This pattern of results implies that $\mathrm{CS}_{\mathbf{2}}$ acts in a secondary inhibitory role either as a discriminative stimulus which modulates responding to a subsequent stimulus or as a distracting stimulus which overshadows or masks the responseeliciting properties of the stimulus which follows.

The present experiments offer no explanation for the prominent differences between secondorder fear conditioning and eyelid conditioning. There is an established literature which demonstrates that the conditional eyelid response is carefully timed to occur just prior to US onset (e.g., Boneau, 1958; Frey, 1970; Frey \& Ross, 1968; Leonard \& Theios, 1967; Martin \& Levey, 1969; Smith, 1968). This response system characteristic may be incompatible with the elicitation of overt responding to a secondorder CS. Even if the second-order CS becomes a signal for US occurrence, the time relationship between the two is inappropriate for eliciting an immediate response.

Sears, Baker, and Frey (1979) have recently demonstrated that the first element of a two-element serial CS develops response-eliciting properties in eyelid conditioning. However, when this stimulus is presented by itself on a test trial, the CR occurs some time after its termination. This "late" response occurs at the time the US would normally occur on a regular serial trial. If second-order conditioning leads to the development of a timed second-order eyelid CR, then this response would also be expected to occur after the termination of the second-order stimulus. The establishment of an appropriate time relationship between the second-order stimulus and US onset requires that a conceptual superimposition of first-order and second-order trials be made. A complex process such as this may not occur in eyelid conditioning or it may occur only to a limited extent. Recent observations (Sears, Baker, \& Frey, 1979, Experiment 4) are consistent with the latter possibility.

\section{REFERENCES}

Boneau, C. A. The interstimulus interval and the latency of the conditioned eyelid response. Journal of Experimental Psychology, 1958, 56, 464-472.

DAVEnPort, J. W. Higher-order conditioning of fear (CER). Psychonomic Science, 1966, 4, 27-28.

Frey, P. W. Within-subject analysis of the CS-US interval in rabbit eyelid conditioning. Learning and Motivation, 1970, 1, 337-345.

FreY, P. W., \& Butler, C. S. Extinction after aversive conditioning: An associative or nonassociative process? Learning and Motivation, 1977, 8, 1-17.
Frey, P. W., \& Ross, L. E. Differential conditioning of the rabbit's eyelid response with an examination of Pavlov's induction hypothesis. Journal of Comparative and Physiological Psychology, 1967, 64, 277-283.

Frey, P. W., \& Ross, L. E. Classical conditioning of the rabbit eyelid response as a function of interstimulus interval. Journal of Comparative and Physiological Psychology, 1968, 65, 246-250.

HEARST, E. Some persistent problems in the analysis of conditioned inhibition. In R. A. Boakes \& M. S. Halliday (Eds.), Inhibition and learning. New York: Academic Press, 1972.

Herendeen, D., \& Anderson, D. C. Dual effects of a secondorder conditioned stimulus: Excitation and inhibition. Psychonomic Science, 1968, 13, 15-16.

KAMIL, A. C. The second-order conditioning of fear in rats. Psychonomic Science, 1968, 10, 99-100.

LEONARD, D. W., \& Theios, J. Effect of CS-US interval shift on classical conditioning of the nictitating membrane in the rabbit. Journal of Comparative and Physiological Psychology, 1967, 63, 355-358.

Maisiak, R., \& Frey, P. W. Second-order conditioning: The importance of stimulus overlap on second-order trials. Animal Learning \& Behavior, 1977, 5, 309-314.

Mantin, I., \& Levy, A. B. The genesis of the classical conditioned response. New York: Pergamon Press, 1969.

McAlliste R, D. E., \& McAllister, W. R. Second-order conditioning of fear. Psychonomic Science, 1964, 1, 383-384.

Myers, J. L. Fundamentals of experimental design. Boston: Allyn and Bacon, 1972.

PAvlov, I. P. Conditioned reflexes (G. V. Anrep, trans.). London: Oxford University Press, 1927. (Dover Publications, 1960.)

Rescorla, R. A. Pavlovian conditioned inhibition. Psychological Bulletin, 1969, 72, 77-94.

Rescorla, R. A. Informational variables in Pavlovian conditioning. In G. H. Bower (Ed.), The psychology of learning and motivation. Advances in research and theory. (Vol. 6). New York: Academic Press, 1972.

RescoRla, R. A. Second-order conditioning: Implications for theories of learning. In F. J. McGuigan \& D. B. Lumsden (Eds.), Contemporary approaches to conditioning and learning. Washington, D.C.: Winston, 1973.

Rizley, R. C., \& Rescorla, R. A. Associations in second-order conditioning and sensory pre-conditioning. Journal of Comparative and Physiological Psychology, 1972, 81, 1-11.

SeArs, R. An automated runway: Responding without postreinforcement goal tracking. Behavior Research Methods \& Instrumentation, 1978, 10, 404-408.

Sears, R., Baker, J., \& Frey, P. W. The eyeblink as a timelocked response: Implications for serial and second-order conditioning. Journal of Experimental Psychology: Animal Behavior Processes, 1979, 5, 43-64.

Sмiтн, M. C. CS-US interval and US intensity in classical conditioning of the rabbit's nictitating membrane response. Journal of Comparative and Physiological Psychology, 1968, 66, 679-687.

Stern, S. D., \& Frey, P. W. Backward conditioning of the rabbit eyelid response: $A$ test using second-order conditioning. Bulletin of the Psychonomic Society, 1978, 11, 231-234.

VanDercar, D. H., Swadlow, H. A., Elster, A., \& Schne Iderman, N. Nictitating membrane and corneo-retinal transducers for conditioning in rabbits. American Psychologist, $1969,24,262-264$.

(Received for publication June 30, 1978; revision accepted November 14,1978 .) 